\title{
Child deaths in South Africa: Lessons from the child death review pilot
}

South Africa (SA) has not met the child mortality target for the Millennium Development Goals, despite having invested substantially in programmes and policies to achieve these targets. The scale-up of the prevention of mother-to-child transmission programmes reduced HIV transmission from mother to child, but this has not been sustained owing to limitations in community-based child health services. ${ }^{[1]}$ Child mortality has declined, but has now plateaued ${ }^{[2]}$ Children continue to die from preventable and treatable causes of death. ${ }^{[3]}$ Current data sources are incomplete, and do not provide information on deaths occurring out of health facilities. ${ }^{[1]}$ The child death review (CDR) pilot explores the pattern of child deaths and informs prevention strategies to improve child survival in SA. In this editorial we draw on the conclusions of the CDR pilot, ${ }^{[4]}$ where multiagency teams were established to investigate non-natural and unexpected deaths referred to two mortuary sites in order to strengthen child health and protection response systems and to prevent child deaths.

Strategies to improve child survival have mainly focused on under-5 deaths, yet our CDR pilot has shown that deaths throughout childhood require attention. The following patterns of child mortality were identified: (i) infanticide in the neonatal period; (ii) acquired natural causes (in particular lower respiratory tract infection (LRTI)) during infancy; (iii) child abuse- and neglect-related deaths in children aged $<5$ years; (iv) road traffic deaths, in particular deaths of pedestrians, as children become older; and $(v)$ homicide and suicide in the older age group ( 15 - 17 years). The CDR investigates each child death using a set of questions that include the medical factors together with the social contributors to each child's death, particularly in sudden unexpected and injury-related deaths. This process requires an understanding of the context or environment in which each death occurred, including factors at each level individual (biological and psychological), family, social, cultural, health and social welfare system - that influence access to care and the care the child received. ${ }^{[5]}$

The neonatal period is well documented as a period of great risk, particularly for preterm infants. We show that preterm infants are at increased risk of dying from LRTIs during the post-neonatal period once they have been discharged home, especially during winter. We have argued ${ }^{[6]}$ that as the state has invested substantially in the care of preterm infants during the neonatal period, it is imperative that research be conducted to identify why these infants die once out of hospital from seemingly preventable natural causes. Social circumstances such as poor living conditions intersect with limited support for mothers and suboptimal quality of community-based services, making preterm infants vulnerable to death from preventable infections such as LRTIs. Although SA has a strategy to re-engineer primary healthcare (PHC) through ward-based PHC outreach teams, its impact is currently limited because of a low healthcare worker-topopulation ratio and lack of training. ${ }^{[1]} \mathrm{A}$ purely biomedical approach to reduce such deaths is therefore inadequate, and our CDR process highlights the need to consider social and behavioural influences in combination with health systems factors. ${ }^{[4]}$ Interviews with families performed as part of the CDR process have revealed a large number of cases where infants with no previous medical history of note were apparently well and were fed and put to bed, but later found dead. This recurring pattern of 'fed, bed, dead' is a grave concern. These deaths are mainly due to LRTI, and while some cases are associated with preterm birth, a number of infants have no identifiable risk factors. It appears that many caregivers are unaware of symptoms and signs in infants that require urgent medical attention. This clearly warrants further research into the clinical aspects of LRTI in order for clinical management of infants to be evidence based. The population of infants dying from natural causes out of hospital and admitted to the Forensic Pathology Service (FPS) in the Western Cape presents a cohort that could provide invaluable insights, which has been noted in previous recent research. ${ }^{[7,8]}$ At present, limited capacity restricts the ability to perform complete detailed postmortem examinations (including full microbiological, virological, biochemical and genetic analyses) of these natural deaths.

The early neonatal period was shown to be a period of increased risk of deaths resulting from abandonment and injury. This finding is supported by the national child homicide study showing that SA had one of the highest reported rates of neonaticide globally. ${ }^{[9]}$ Neonaticide is the killing of a newborn within the first 6 days of life, and infanticide the killing of a child in the first year of life. Both these acts are a form of child abuse, whether the killing was deliberate or the death due to a deliberate omission of care, e.g. when a baby is abandoned without care, protection or supervision. ${ }^{[9]}$ Infanticide or abandonment of a newborn is far more common than the CDR pilot suggests, as many infants are 'dumped' in sewers, refuse dumps and dirt bins, and the pilot only identified remains brought to a mortuary. Despite SA's liberal termination of preganancy legislation and the availability of community-based contraception services, it would appear that we are not meeting the needs of large numbers of women. We need to examine maternal and mental health services for pregnant women and determine the appropriate support services required by women in communities to decrease infanticide.

Child deaths related to abuse and neglect deaths were common in the under-5 age group, highlighting the vulnerability of young children to violence and neglect in the home. Physical violence under the guise of discipline is common in SA, and regarded as an acceptable parenting practice. ${ }^{[10]}$ Banning corporal punishment in the home is the first step towards making the home safer for children, and should be a priority in conjunction with primary prevention interventions to reduce the risk of children being exposed to violence in the home. Parenting programmes that enhance the parent-child relationship and reduce harsh parenting practices have been shown to be effective in SA. ${ }^{[11]}$ Enhancing current parenting practices and support systems for families through the early identification of vulnerable families is critical to prevent fatal child abuse. The contribution of neglect to child mortality, and in particular sudden unexpected deaths of infants (SUDIs), is difficult to determine accurately, and this has also been highlighted internationally. The CDR process, through a multiagency review and co-ordinated response to the investigation and management of suspected abuse and neglect cases, facilitated an increase in the identification of child deaths from neglect. The biological cause of death on its own in a SUDI is unable to provide the full picture of the circumstances leading to the child's death, and the Road To Health booklet, supporting health data and the social circumstances, together with an investigation into the care of the child, provided us with a better understanding of the context in which children are dying.

Legally, sudden unexpected deaths must be referred to the nearest FPS (mortuary) for a medicolegal investigation. ${ }^{[12]}$ The difference 
between referral patterns of natural deaths at the two sites in our pilot has raised concern with regard to SUDIs and the need to create awareness on the part of medical colleagues and communities of the definition of a SUDI as an unnatural death. ${ }^{[4]}$ This difference may well extend beyond the two pilot sites and be a much wider occurrence throughout provinces. Anecdotally, the experiences of the forensic pathologists involved in this study suggest that referrals of SUDI cases to the FPS occur much more commonly in the Western Cape than in KwaZulu-Natal. From personal experience (LJM serves as a member of the National Forensic Pathology Service Committee) and involvement in national mortality-based studies of two of the authors (SM and LJM), it is suggested that the Western Cape referral pattern is different from the national referral pattern in that most SUDIs are not referred to the FPS, but declared as natural deaths by medical practitioners in the community, and are therefore never brought to the attention of the health surveillance system. ${ }^{[13,14]} \mathrm{A}$ concern is the potential for child homicides, in particular deaths from neglect, to remain undetected. This may also place other children in the family at risk.

Injury deaths among older children (10 - 17 years) are a concern. In our review there were 11 suicides (7\% of the non-natural deaths), including two 9-year-old children. Deliberate self-harm and suicide in children aged $<10$ years is unusual, establishing the intent of the child after their death is impossible, and the death could be related to other factors. ${ }^{[15]}$ Not much is known about suicides in this young age group, and understanding the underlying risk factors for young children is critical to inform interventions to prevent such deaths. Homicide due to interpersonal violence was the leading cause of injury death in this pilot, and mainly affected young men. Preventing male-on-male violence is critical in the context of high levels of crime and violence in many communities, where children are exposed to violence on a daily basis both in their homes and in the community. Boys in particular are exposed to adverse childhood experiences such as neglect, harsh parenting and abuse, and this contributes to the shaping of violent masculinities. ${ }^{[16]}$ Multipronged evidence-based prevention strategies to strengthen families and equip parents with the skills to use positive discipline may reduce such pathways.

The CDR has shown the potential to increase the accuracy of ascertaining causes of death in children and to reduce undetermined or ill-defined causes, to complement the Child Healthcare Problem Identification Programme (Child PIP) audit of in-hospital child deaths. It improves our ability to identify cases of abuse and neglect so that appropriate action may be taken, and also the circumstances that place children at high risk so that strategies can be put in place to minimise this risk. Data collected from the CDR process are an important barometer for the wellbeing of children in our society, and the study reported on in this issue ${ }^{[4]}$ portrays a grim reality. There is clearly a lack of understanding and awareness regarding the definitions of unnatural deaths according to the Regulations for Forensic Pathology practice, and all stakeholder agencies need to disseminate the requirements and mandates of the statutory obligations of healthcare practitioners. These agencies include the national and provincial departments of health responsible for the FPS, as well as the clinical managers of health services, the National Prosecuting Authority, the Department of Justice (inquest magistrates and prosecutors) and the South African Police Service.

\section{Shanaaz Mathews}

Children's Institute, Faculty of Health Sciences, University of

Cape Town, South Africa

\section{Lorna J Martin}

Division of Forensic Medicine and Toxicology, Faculty of Health

Sciences, University of Cape Town, South Africa

\section{David Coetzee}

Health Impact Assessment, Western Cape Department of Health, Cape Town, and School of Public Health and Family Medicine, Faculty of Health Sciences, University of Cape Town, South Africa

\section{Chris Scott}

Department of Paediatrics and Child Health, Faculty of Health

Sciences, University of Cape Town, South Africa

\section{Yasheen Brijmohun}

Forensic Pathology Services, KwaZulu-Natal Department of Health, Durban; and Department of Forensic Medicine, School of Laboratory Medicine and Medical Sciences, College of Health Sciences, Nelson $R$ Mandela School of Medicine, University of KwaZulu-Natal, Durban, South Africa

\section{Corresponding author: S Mathews (shanaaz.mathews@uct.ac.za)}

1. Doherty T, Kroon M, Rhoda N, Sanders D. Ending preventable child deaths in South Africa: What role can ward-based outreach teams play? S Afr Med J 2016;106(7):672-674. DOI:10.7196/SAMJ.2016. v106i7.10790

2. Chopra M, Daviaud E, Pattinson R, Fonn S, Lawn JE. Saving the lives of South Africa's mothers, babies, and children: Can the health system deliver? Lancet 2009;374(9692):835-846. DOI:10.1016/S01406736(09)61123-5

3. Nannan N, Dorrington R, Laubscher R, et al. Under-5 Mortality Statistics in South Africa: Shedding . Nannan N, Dorrington R, Laubscher R, et al. Under-5 Mortality Statistics in South Africa: Shedding
Some Light on the Trends and Causes 1997-2007. Cape Town: South African Medical Research Council, 2012.

4. Mathews S, Martin L, Coetzee D, et al. The South African child death review pilot: A multi-agency approach to strengthen healthcare and protection for children. S Afr Med J 2016;106(9):895-899. DOI:10.7196/SAMJ.2016.v106i9.11234

5. Sidebotham P, Fraser J, Covington T, et al. Understanding why children die in high-income countries. Lancet 2014;384(9946):915-927. DOI:10.1016/S0140-6736(14)60581-X

6. Velaphi S, Rhoda N. Reducing neonatal deaths in South Africa - are we there yet, and what can be done? S Afr J Child Health 2012;6(3):67-71. DOI:10.7196/SAJCH.493

7. Groenewald P, Bradshaw D, Neethling I, et al. Linking mortuary data improves vital statistics on cause of death of children under five years in the Western Cape Province of South Africa. Trop Med Int Health 2016;21(1):114-121. DOI:10.1111/tmi.12624

8. Reid AE, Hendricks MK, Groenewald P, Bradshaw D. Where do children die and what are the causes? Reid AE, Hendricks MK, Groenewald P, Bradshaw D. Where do children die and what are the causes?
Under-5 deaths in the Metro West geographical service area of the Western Cape, South Africa, 2011. Under-5 deaths in the Metro West geographical service area of the Western

9. Abrahams N, Mathews S, Martin LJ, Lombard C, Nannan N, Jewkes R. Gender differences in 9. Abrahams N, Mathews S, Martin LJ, Lombard C, Nannan N, Jewkes R. Gender differences in
homicide of neonates, infants, and children under $5 \mathrm{y}$ in South Africa: Results from the crosssectional 2009 National Child Homicide Study. PLoS Med 2016;13(4):e1002003. DOI:10.1371/ journal.pmed. 1002003

10. Seedat M, van Niekerk A, Jewkes R, Suffla S, Ratele K. Violence and injuries in South Africa: Prioritising an agenda for prevention. Lancet 2009;374(9694):1011-1022. DOI:10.1016/S01406736(09)60948-X

11. Wessels I, Ward CL. A 'best buy' for violence prevention - evaluating parenting skills programmes. SA Crime Quarterly 2015;54:17-28. DOI:10.4314/sacq.v54i1.2

12. Republic of South Africa. Regulations to the National Health Act 61 of 2003. Pretoria: Government Gazette, 2007. http://www.saflii.org/za/legis/consol_reg/nha61o2003rangnr636590.pdf (accessed 8 May 2016).

13. Matzopoulos R, Prinsloo M, Pillay-van Wyk V, et al. Injury-related mortality in South Africa: A retrospective descriptive study of postmortem investigations. Bull World Health Organ 2015;93:303313. DOI:10.2471/BLT.14.145771

14. Mathews S, Abrahams N, Jewkes R, Martin LJ, Lombard C. The epidemiology of child homicides in South Africa. Bull World Health Organ 2013;91:562-568. DOI:10.2471/BLT.12.117036

15. Sidebotham P, Fraser J, Fleming P, Ward-Platt M, Hain R. Patterns of child death in England and Wales. Lancet 2014;384(9946):904-914. DOI:10.1016/S0140-6736(13)61090-9

16. Mathews S, Jewkes R, Abrahams N. 'I had a hard life': Exploring childhood adversity in the shaping of masculinities among men who killed an intimate partner in South Africa. Br J Criminol 2011;51(6):960-977. DOI:10.1093/bjc/azr051

S Afr Med J 2016;106(9):851-852. DOI:10.7196/SAMJ.2016.v106i9.11382 